\title{
Active, but not passive cigarette smoking was inversely associated with mammographic density
}

\author{
Lesley M. Butler · Ellen B. Gold · Shannon M. Conroy • \\ Carolyn J. Crandall · Gail A. Greendale • Nina Oestreicher • \\ Charles P. Quesenberry Jr. • Laurel A. Habel
}

Received: 20 May 2009/Accepted: 22 October 2009/Published online: 14 November 2009

(C) The Author(s) 2009. This article is published with open access at Springerlink.com

\begin{abstract}
Purpose The opposing carcinogenic and antiestrogenic properties of tobacco smoke may explain why epidemiologic studies have not consistently reported positive associations for active smoking and breast cancer risk. A negative relation between mammographic density, a strong breast cancer risk factor, and active smoking would lend support for an antiestrogenic mechanism.

Methods We used multivariable linear regression to assess the associations of active smoking and secondhand smoke (SHS) exposure with mammographic density in 799 pre- and early perimenopausal women in the Study of Women's Health Across the Nation (SWAN).

Results We observed that current active smoking was associated with $7.2 \%$ lower mammographic density, compared to never active smoking and no SHS exposure $(p=0.02)$. Starting to smoke before 18 years of age and having smoked $\geq 20$ cigarettes/day were also associated with statistically significantly lower percent densities.
\end{abstract}

\author{
L. M. Butler $(\bowtie)$ \\ Department of Environmental and Radiological Health Sciences, \\ Colorado State University, 1681 Campus Delivery, Fort Collins, \\ CO 80523-1681, USA \\ e-mail: Lesley.Butler@colostate.edu \\ E. B. Gold · S. M. Conroy \\ Department of Public Health Sciences, University of California, \\ Davis, CA, USA \\ e-mail: ebgold@ucdavis.edu \\ S. M. Conroy \\ e-mail: smconroy@ucdavis.edu \\ C. J. Crandall \\ Division of General Internal Medicine, David Geffen School \\ of Medicine at UCLA, Los Angeles, CA, USA \\ e-mail: ccrandall@mednet.ucla.edu
}

Among nulliparous women having smoked $\geq 20$ cigarettes/ day was associated with $23.8 \%$ lower density, compared to having smoked $\leq 9$ cigarettes/day $(p<0.001)$.

Conclusions Our findings support the hypothesis that tobacco smoke exerts an antiestrogenic effect on breast tissue, but counters the known increased risk of breast cancer with smoking prior to first full-term birth. Thus, our data suggest that the antiestrogenic but not the carcinogenic effects of smoking may be reflected by breast density.

Keywords Breast cancer risk factor - Breast density · Cigarette smoking $\cdot$ Mammographic density .

Secondhand smoke

\section{Introduction}

In vivo data provide evidence that several tobacco smoke constituents act as breast carcinogens [1, 2]. Although cigarette smoking is a likely risk factor for breast cancer

G. A. Greendale

Division of Geriatrics, David Geffen School of Medicine

at UCLA, Los Angeles, CA, USA

e-mail: ggreenda@mednet.ucla.edu

N. Oestreicher

Genentech, Inc., South San Francisco, CA, USA

e-mail: hill.nina@gene.com

C. P. Quesenberry Jr. · L. A. Habel

Division of Research, Kaiser Permanente Medical Care Program,

Oakland, CA, USA

e-mail: charles.quesenberry@kp.org

L. A. Habel

e-mail: laurel.habel@kp.org 
among pre- and postmenopausal women [3-5], the observational data are by no means consistent $[6,7]$. However, smoking exposure during the pre-partum period, or time prior to a woman's first full-term birth (FFTB), when breast tissue is less differentiated [8], appears to be most relevant for breast cancer risk [9-13]. Duration and early age at secondhand smoke (SHS) exposure among women who have never actively smoked have also been associated with a modest increased risk of breast cancer [14, 15].

The complex mixture of chemicals in tobacco smoke condensate include not only compounds with carcinogenic properties [1] but also compounds with antiestrogenic properties [16] that may act by disturbing gonadotropin release [17-19] or inhibiting aromatase activity [20]. Observational studies provide more consistent evidence for an indirect antiestrogenic effect of tobacco smoke. For example, smoking has been associated with health issues related to menstrual and ovarian disruption, such as infertility [21], earlier age at menopause [22], and decreased bone density [23]. In contrast, few data support direct effects, such as lower serum estradiol levels among premenopausal current smokers versus nonsmokers [24-26].

Percent mammographic density, or the percentage of total breast tissue area that is radiologically dense, has been associated with an average four- to six-fold increase in breast cancer risk, when comparing $\geq 60 \%$ to little or no density [27]. While current smoking has been consistently reported to be inversely associated with percent mammographic density among premenopausal women [28-31], less consistent findings have been reported among postmenopausal women, with one study reporting an inverse association [32], and others reporting no association [29, $31,33]$. The inconsistently reported positive associations between smoking and breast cancer risk and inverse associations between smoking and breast density suggest dual, opposing effects of tobacco smoke on breast tissue.

Few data are available that go beyond evaluating dichotomized smoking status and mammographic density. In addition, most prior studies of smoking and mammographic density have not evaluated SHS exposure, with one exception [28]. The aim of this study was to use detailed active smoking and SHS exposure data to evaluate whether smoking status, and other smoking characteristics were associated with percent mammographic density in a multiethnic cohort of pre- and early perimenopausal women.

\section{Materials and methods}

\section{Study population}

This study was conducted among a subset of participants enrolled in the Study of Women's Health Across the
Nation (SWAN) who provided mammograms. SWAN is a community-based, longitudinal study designed to evaluate women though the menopausal transition [34]. Three SWAN sites, University of California Davis-Kaiser (Oakland), University of California Los Angeles (Los Angeles) and University of Pittsburgh (Pittsburgh), participated in the mammographic density ancillary study. To be eligible to enter the SWAN cohort, women had to be between 42 and 52 years of age, to have reported having had a menstrual period and no use of exogenous hormones within the 3 months prior to recruitment, and to have identified their primary race as African-American (Pittsburgh), Japanese (Los Angeles), Chinese (Oakland), or Caucasian (all sites). To identify women from the general population, two sites (Los Angeles, Pittsburgh,) used random digit dialingsampling, and one site selected randomly from a healthcare organization membership listing (Oakland). Of the 1,248 women in follow-up at these three SWAN sites at the time of enrollment into the ancillary study (i.e. at the fifth or sixth annual follow-up visit), $85 \%$ agreed to participate. Of those who participated, 1,005 (95\%) had at least one eligible mammogram for density assessment.

Mammographic density declines through the menopausal transition [35]. For this reason, women were included in these analyses only if they were pre- or early perimenopausal at the time of their index mammogram to evaluate tobacco smoke exposure at a time closest to that of peak breast density. Based on SWAN criteria [36], premenopausal status was defined as menses in the past 3 months, with no change over the past year in predictability of menstrual periods [37, 38]. Early perimenopausal status was defined as menses in the past 3 months with some change in the predictability of menstrual periods over the past year.

A total of 799 pre- or early perimenopausal women had an eligible mammogram and complete smoking data available for these analyses (391 non-Hispanic white, 60 African-American, 169 Japanese, and 179 Chinese). Both the core SWAN protocol and the protocol for the mammographic density ancillary study were approved by Institutional Review Boards at all institutions participating in this ancillary study.

\section{Exposure assessment}

Active smoking history and secondhand smoke exposure

Active smoke exposure was assessed using a self-administered questionnaire at baseline and each subsequent follow-up visit using seven questions adapted from the American Thoracic Society [39]. SHS exposure within the past 7 days was assessed among never- or former-active smokers using a self-administered questionnaire at baseline 
and at follow-up visit 03 using seven questions adapted from a validated questionnaire [40]. Participants were asked about number of people, days and hours of tobacco smoke exposure inside the home and while at work, and hours of exposure while at places other than home or work (including meetings, restaurants, bars, parties, etc.). Participant responses at baseline $(n=676)$ or the follow-up visit $(n=267)$ closest to the woman's index mammogram were used to determine smoking status (never/no SHS, never/with SHS, former, current), age at initiation, smoking intensity (cigarettes/day), years smoked, pack-years, years since quitting (among former-active smokers), and person-hours of SHS exposure (among never and former active smokers). Ever-active smokers were defined as having smoked a total of at least 20 packs of cigarettes over their lifetime, or at least one cigarette per day for at least 1 year. Former-active smokers were defined as ever-active smokers who reported no longer smoking at the time of interview. Only seven women changed from current to former active smokers, and one woman changed from former to current active smoker status during follow-up, among the women with smoking data from a follow-up visit. Presence of SHS exposure was defined as at least one total person-hour of SHS exposure during the past 7 days. Person-hours of SHS were calculated as follows: for example, if a participant reported being exposed to tobacco smoke by one person for $2 \mathrm{~h}$ every day over the past 7 days in their home, no exposure while at work, and $3 \mathrm{~h}$ for 1 day over the past 7 days while at a restaurant, then the total person-hours of SHS exposure would be 17. Changes from no SHS exposure at baseline to $\geq 1$ person-hours during follow-up were reported by 16 women, and 13 women changed from $\geq 1$ person-hours to no SHS exposure.

\section{Other factors}

At baseline (1996-1997), in-person, interviewer-administered questionnaires were used to obtain information on date of birth, race/ethnicity, highest level of education, family history of breast cancer, and menstrual and reproductive factors. At baseline and at each annual follow-up visit starting in 1997, information was collected on annual household income, hormone use, gynecologic events (including menopausal status), weight and height, and alcohol use. For annually collected data, we used the responses collected at the visit closest to a woman's index mammogram.

\section{Mammographic density}

Eligible mammograms were those taken as part of routine medical care during the period from 2 years prior to the baseline examination through 2 years after annual followup visit 06 . If multiple mammograms were available for a given participant, then the mammogram closest to, either preceding or following, the baseline visit was selected.

Quantitative assessment was made by Martine Salane, an established expert in the techniques of measuring mammographic density [41]. Ms. Salane's measurements have been highly correlated with computer-assisted density measurements $(r=0.90)$ [42]. The total area of the breast and the areas of dense breast were measured with a compensating polar planimeter (LASICO, Los Angeles, CA) on the craniocaudal view of the right breast. Mammograms from the left breast were used for density assessments when films from the right breast were unavailable $(n=81)$. Percent density was calculated by dividing the area of dense breast by the total area of the breast and multiplying by 100 .

\section{Statistical methods}

The primary goal of these analyses was to assess whether tobacco smoke exposure was related to percent mammographic density. Transformation was not needed to normalize the distribution of percent mammographic density. Statistical computing was conducted using SAS version 9.1 (SAS Institute Inc., Cary, NC, USA).

\section{Independent variables}

The main independent variables of interest were smoking status (never-active/without SHS, never-active/with SHS, former-active, current-active), person-hours of SHS exposure (among never- and former-active smokers, separately), years since stopped smoking (among former-active smokers), and among ever-active smokers: age at starting to smoke ( $\geq 18,<18$ years), average number of cigarettes smoked per day $(\leq 9,10-19, \geq 20)$, years smoked $(\leq 9,10$ $19,20-29, \geq 30)$, and pack-years of smoking $(<, \geq$ median $=7.5$ ). We also assessed whether age at starting to smoke with respect to age at menarche and age at FFTB was important in analyses stratified by parity.

\section{Covariates}

The following variables were assessed as potential confounders: age, body mass index (BMI), race/ethnicity, study site, education level, household income, age at menarche, parity, menopausal status, oral contraceptive use, other hormone use, alcohol consumption, and family history of breast cancer [43-46]. In addition, a combined variable race/ethnicity-study site was created, because each study site recruited women from a single race/ethnic group in addition to non-Hispanic whites. For example, Chinese 
women were recruited in Oakland, Japanese women in Los Angeles, and African-American women in Pittsburgh.

Bivariate analyses were conducted to study mean mammographic density levels in relation to each covariate using ANOVA or simple linear regression, depending on variable type. If a covariate was associated with mammographic density based on the bivariate analyses, it was individually added into a base model with smoking status (never-active smoker/no SHS, never-active smoker/with SHS, former active, current active). The following covariates were included in the final adjusted model, because they resulted in a $10 \%$ or greater change in the beta estimates for smoking status: age (40-44, 45-49, 5055 years), BMI (continuous and $<25.0,25-29.9, \geq 30.0 \mathrm{~kg} /$ $\mathrm{m}^{2}$ ), race/ethnicity-study site (non-Hispanic white-Oakland, Chinese-Oakland, non-Hispanic white-Los Angeles, Japanese-Los Angeles, non-Hispanic white-Pittsburgh, African American-Pittsburgh). Additionally, the following covariates were added because of their associations with smoking status and mammographic density in these data [47]: age at menarche $(<12,12,13, \geq 14$ years $)$, parity $(0$, $1-2, \geq 3$ full-term births), alcohol consumption (abstainer, $\geq 1$ drinks/week), and oral contraceptive use (never, ever). Finally, we examined whether the association between percent mammographic density and smoking status varied by the following factors: age, BMI, race/ethnicity-study site, menopausal status, parity and alcohol consumption by performing both stratified analyses, and fitting of interaction terms in adjusted models.

\section{Results}

Our cohort of 799 women had a mean age of 47 years, almost half were non-Hispanic white, and a majority were classified as never-active smokers, with $37 \%$ of neveractive smokers reporting at least one person-hour of SHS exposure in the last 7 days (Table 1). Percent mammographic density was nearly normally distributed (skewness $=-0.1 ; \quad$ kurtosis $=0.9$ ), with a mean of 44.4 (standard deviation $=20.4$ ) and a median of 45.9 (interquartile range $=29.3$ ). We have previously reported that percent mammographic density was inversely associated with older age, higher BMI, previous oral contraceptive use, and greater number of births [48].

Mean percent mammographic density decreased across smoking status categories associated with increased tobacco smoke exposure, with the lowest percent density among current active smokers (Table 1). Ever-active smokers, compared to never-active smokers/without SHS were more likely to be non-Hispanic white and less likely to be Chinese, had lower education, higher BMI, were more likely to consume alcohol, ever use oral contraceptives, or have a family history of breast cancer, and less likely to have had a full-term birth (Table 1). Differences by SHS exposure among never-active smokers were similar, for example, never-active smokers were more likely to be exposed to SHS if they were non-Hispanic white, had higher BMI, and consumed alcohol.

Results of the unadjusted linear regression models indicated that, compared to never-active smokers without SHS, the following groups had increasing inverse associations with percent density: never active with SHS, former active, and current active, respectively (Table 2). After adjustment for potential confounders, all beta estimates for smoking status categories were attenuated but remained statistically significant (Table 2). No difference was observed in the magnitude of association for former-active (adjusted beta $=-2.12$ ) and current-active (adjusted beta $=-6.80$ ), smokers when never-active smokers (regardless of SHS exposure) were used as the referent group $(p<0.01)$.

Amount of person-hours of SHS exposure among neveractive smokers was inversely associated with percent density, but the beta for $>3$ person-hours versus no SHS was attenuated to the null after adjustment for potential confounders (Table 2). The associations with smoking status were not meaningfully different across strata of age, $\mathrm{BMI}$, race/ethnicity, menopausal status, or alcohol consumption (data not shown). The associations with smoking status were also similar when we restricted analyses to nonHispanic whites ( $n=391$ ) (adjusted beta for current-active smoker versus never smoker/no $\mathrm{SHS}=-7.40, p$ for smoking status $=0.08$ ).

Among former-active smokers, we did not observe a trend for years since stopped smoking and percent density (Table 2). Among ever-active smokers, characteristics inversely associated with percent density included younger age at starting to smoke, more cigarettes smoked per day, and more pack-years (Table 2). Only the inverse association with pack-years lost statistical significance after adjusting for potential confounders (Table 2).

Next, we evaluated whether associations between different measures of active smoking characteristics and percent density differed for parous and nulliparous women (Table 3). Starting to smoke within 5 years of menarche was not associated with percent density among either nulliparous or parous ever-active smokers. A non-statistically significant inverse association was observed for starting to smoke before a FFTB. Earlier age at starting to smoke was inversely associated with percent density among both groups, with a stronger association among parous ever-active smokers ( $p$ for interaction by parity $=0.6)$. The strongest inverse association was observed for smoking intensity among nulliparous ever smokers, with a trend of lower density with more cigarettes per day ( $p$ for interaction by parity $<0.001$ ). 
Table 1 Distribution of study population characteristics ${ }^{\mathrm{a}}$ by smoking status

\begin{tabular}{|c|c|c|c|c|c|}
\hline & Never smoker/no SHS ${ }^{b}$ & Never smoker/with SHS ${ }^{b}$ & Former smoker & Current smoker & $\begin{array}{l}p \text {-value comparing never/no } \\
\text { SHS to ever smokers }\end{array}$ \\
\hline$n(\%)$ & $344(43)$ & $203(25)$ & $179(22)$ & $73(9)$ & \\
\hline \multirow{2}{*}{$\begin{array}{l}\text { Mean percent mammographic } \\
\text { density }(95 \% \mathrm{CI})^{c}\end{array}$} & $48.5(46.3,50.6)$ & $43.1(40.3,45.8)$ & $40.7(37.7,43.6)$ & $38.4(33.7,43.0)$ & $<0.001$ \\
\hline & $\%$ & $\%$ & $\%$ & $\%$ & \\
\hline
\end{tabular}

\section{Characteristics}

Age (years)

$40-44$
$45-49$
$50-55$

50-55

Race/ethnicity

Non-Hispanic white

African-American

Chinese

Japanese

$\begin{array}{rr}90 & 26 \\ 198 & 58 \\ 56 & 16\end{array}$

$\begin{array}{rr}53 & 26 \\ 115 & 57 \\ 35 & 17\end{array}$

$\begin{array}{rrrr}44 & 25 & 23 & 32 \\ 96 & 54 & 41 & 56 \\ 39 & 22 & 9 & 12\end{array}$

0.63

Highest education level

High school graduate or less

Some college

$\begin{array}{rr}132 & 38 \\ 11 & 3 \\ 131 & 38 \\ 70 & 20\end{array}$

College graduate or more

Body mass index, $\mathrm{kg} / \mathrm{m}^{2}$

$$
\begin{aligned}
& <25.0 \\
& 25.0-29.9 \\
& \geq 30
\end{aligned}
$$

$\begin{array}{rr}56 & 16 \\ 87 & 25 \\ 201 & 58\end{array}$

109

109
18
37
39

54
9
18
19

$\begin{array}{rrrr}114 & 64 & 36 & 49 \\ 16 & 9 & 15 & 21 \\ 9 & 5 & 2 & 3 \\ 40 & 22 & 20 & 27\end{array}$

Alcohol, drinks/week

Abstainer
$\geq 1$

Age at menarche, years

$<12$
12
13
$>13$
Parity

Nulliparous
Parous

1-2 full-term births

$\geq 3$ full-term births

Menopausal status

Early perimenopausal

Premenopausal

$\begin{array}{rrrr}228 & 67 & 100 & 50 \\ 71 & 21 & 51 & 25 \\ 40 & 12 & 51 & 25\end{array}$

40

$\begin{array}{rl}35 & 17 \\ 61 & 30 \\ 107 & 53 \\ & \\ 100 & 50 \\ 51 & 25 \\ 51 & 25\end{array}$

$\begin{array}{rr}277 & 81 \\ 66 & 19\end{array}$

133

67

67

67

34

$\begin{array}{rrrr}61 & 18 & 47 & 23 \\ 89 & 26 & 58 & 29 \\ 112 & 33 & 60 & 30 \\ 79 & 23 & 38 & 19\end{array}$

$\begin{array}{rrr}51 & 15 & 40 \\ 293 & 85 & 163 \\ 213 & 62 & 113 \\ 80 & 23 & 50\end{array}$

20
80
56
25

$\begin{array}{rlll}19 & 11 & 19 & 26 \\ 57 & 32 & 31 & 43 \\ 103 & 58 & 23 & 32\end{array}$

0.04

$<0.001$

$\begin{array}{llll}84 & 48 & 37 & 52 \\ 48 & 27 & 18 & 25 \\ 43 & 25 & 16 & 23\end{array}$

$<0.001$

$\begin{array}{rrrr}110 & 62 & 37 & 52 \\ 68 & 38 & 34 & 48\end{array}$

0.06

$\begin{array}{llll}42 & 24 & 15 & 21 \\ 56 & 31 & 25 & 35 \\ 47 & 26 & 15 & 21 \\ 34 & 19 & 17 & 24\end{array}$

$\begin{array}{rrrrr}42 & 23 & 14 & 19 & \\ 137 & 77 & 58 & 81 & 0.02 \\ 100 & 56 & 39 & 54 & 0.06 \\ 37 & 21 & 19 & 26 & \end{array}$

$\begin{array}{rrrrrrrr}179 & 52 & 118 & 58 & 97 & 54 & 42 & 58 \\ 165 & 48 & 85 & 42 & 82 & 46 & 31 & 42\end{array}$

Ever used oral contraceptives

$\begin{array}{lrrrrrrrr}\text { No } & 111 & 32 & 53 & 26 & 29 & 16 & 16 & 22 \\ \text { Yes } & 232 & 67 & 148 & 73 & 148 & 83 & 57 & 78\end{array}$

Breast cancer family history

None

$\geq 1$ first degree relative

$\geq 1$ second degree relative

$\begin{array}{rrrr}251 & 74 & 143 & 71 \\ 57 & 17 & 35 & 17 \\ 32 & 9 & 24 & 12\end{array}$

$\begin{array}{rrrr}120 & 68 & 47 & 64 \\ 42 & 24 & 19 & 26 \\ 15 & 8 & 7 & 10\end{array}$

${ }^{\text {a }}$ Data was from baseline (race/ethnicity, education, age at menarche, parity, oral contraceptive use, family history, secondhand smoke exposure) or from the closest annual follow-up visit closest to the woman's index mammogram (age, body mass index, alcohol, menopausal status, active smoking)

b Secondhand smoke (SHS) exposure is based on self-reported person-hours (\#people $\mathrm{x}$ \#days $\times$ hours) of exposure in past 7 days at home, work and other sources

c Confidence interval, CI 
Table 2 Smoking in relation to percent mammographic density

\begin{tabular}{|c|c|c|c|c|c|c|c|}
\hline & $n(\%)$ & $\begin{array}{l}\text { Univariate models } \\
\text { Beta estimate }(\mathrm{SE})^{\mathrm{a}}\end{array}$ & $p$-value & $\begin{array}{l}\text { Adjusted models } \\
\text { Beta estimate }(\mathrm{SE})^{\mathrm{b}}\end{array}$ & $p$-value & $\begin{array}{l}\text { Adjusted mean } \\
\text { percent density }^{\mathrm{c}}\end{array}$ & $95 \% \mathrm{CI}^{\mathrm{d}}$ \\
\hline Smoking status & & & $<0.001$ & & 0.02 & & \\
\hline Never smoker/no SHS ${ }^{\mathrm{e}}$ & $344(43)$ & 0.0 & & 0.0 & & 45.6 & $43.8,47.5$ \\
\hline Never smoker/with SHS & $203(25)$ & $-5.38(1.78)$ & & $-0.94(1.60)$ & & 44.9 & $42.6,47.3$ \\
\hline Former smoker & $179(22)$ & $-7.80(1.85)$ & & $-2.53(1.71)$ & & 43.3 & $40.8,45.8$ \\
\hline Current smoker & $73(9)$ & $-10.08(2.59)$ & & $-7.24(2.41)$ & & 38.8 & $34.7,42.9$ \\
\hline \multicolumn{8}{|l|}{ Never smokers } \\
\hline SHS exposure, person-hours per week & & & 0.02 & & 1.0 & & \\
\hline 0 & $344(63)$ & 0.0 & & 0.0 & & 45.7 & $43.8,47.6$ \\
\hline 1 & $71(13)$ & $-5.17(2.60)$ & & $-0.35(2.29)$ & & 44.8 & $40.9,48.7$ \\
\hline $2-3$ & $63(12)$ & $-7.05(2.74)$ & & $-1.44(2.47)$ & & 43.8 & $39.6,48.0$ \\
\hline$>3$ & $69(13)$ & $-4.08(2.63)$ & & $-0.43(2.39)$ & & 45.6 & $41.6,49.6$ \\
\hline \multicolumn{8}{|l|}{ Former smokers } \\
\hline Years since stopped smoking & & & 0.15 & & 0.11 & & \\
\hline$\geq 21$ & $54(32)$ & 0.0 & & 0.0 & & 42.6 & $38.1,47.1$ \\
\hline $16-20$ & $33(19)$ & $3.19(4.46)$ & & 3.37 (3.92) & & 45.3 & $39.4,51.1$ \\
\hline $11-15$ & $34(20)$ & $-7.79(4.42)$ & & $-5.65(3.94)$ & & 36.4 & $30.6,42.3$ \\
\hline$\leq 10$ & 49 (29) & $-2.24(3.98)$ & & $-4.55(3.44)$ & & 37.0 & $32.3,41.7$ \\
\hline \multicolumn{8}{|l|}{ Ever smokers } \\
\hline Age starting to smoke, years & & & 0.01 & & 0.04 & & \\
\hline$\geq 18$ & $148(60)$ & 0.0 & & 0.0 & & 41.9 & $39.2,44.6$ \\
\hline$<18$ & $100(40)$ & $-6.51(2.63)$ & & $-4.87(2.38)$ & & 36.4 & $33.0,39.8$ \\
\hline Average cigarettes smoked per day & & & 0.04 & & 0.02 & & \\
\hline$\leq 9$ & $77(31)$ & 0.0 & & 0.0 & & 43.6 & $39.8,47.4$ \\
\hline $10-19$ & $73(29)$ & $-5.79(3.34)$ & & $-5.68(2.89)$ & & 39.2 & $35.3,43.2$ \\
\hline$\geq 20$ & $74(29)$ & $-8.17(3.33)$ & & $-8.09(2.91)$ & & 36.3 & $32.4,40.2$ \\
\hline Years smoked & & & 0.6 & & 0.3 & & \\
\hline$\leq 9$ & $60(24)$ & 0.0 & & 0.0 & & 43.5 & $39.2,47.8$ \\
\hline $10-19$ & $75(30)$ & $-4.16(3.56)$ & & $-2.69(3.07)$ & & 39.7 & $35.9,43.5$ \\
\hline $20-29$ & $79(31)$ & $-3.73(3.52)$ & & $-5.69(3.04)$ & & 37.3 & $33.6,41.1$ \\
\hline$\geq 30$ & $33(13)$ & $-5.01(4.46)$ & & $-3.75(4.09)$ & & 37.8 & $31.5,44.2$ \\
\hline Pack-years smoked & & & 0.03 & & 0.15 & & \\
\hline$<\operatorname{Median}^{\mathrm{f}}$ & $108(50)$ & 0.0 & & 0.0 & & 41.9 & $38.5,45.3$ \\
\hline$\geq$ Median & $110(50)$ & $-6.15(2.78)$ & & $-3.61(2.48)$ & & 37.3 & $34.4,40.3$ \\
\hline
\end{tabular}

${ }^{a}$ Parameter estimates for each factor modeled individually, in separate models. $S E$ standard error

b Parameter estimates for each factor modeled individually, in separate models, and adjusted for age, body mass index, race/ethnicity-study site, age at menarche, parity, alcohol consumption, and oral contraceptive use. $S E$ standard error

${ }^{c}$ Mean values are adjusted for age, body mass index, race/ethnicity-study site, age at menarche, parity, alcohol consumption, and oral contraceptive use

${ }^{\mathrm{d}}$ Confidence interval, CI

e Secondhand smoke (SHS) exposure is based on self-reported person-hours (\#people $\times$ \#days $\times$ hours) of exposure in past 7 days at home, work and other sources

${ }^{\mathrm{f}}$ Median $=7.5$ pack-years

\section{Discussion}

Using cross-sectional data from a cohort of pre- and early perimenopausal women, we observed that current active smoking was associated with a statistically significant, 7.2 percent lower mammographic density, compared to never having actively smoked and without SHS exposure. In addition, starting to smoke before 18 years of age (vs. $\geq 18$ years), and having smoked 20 or more cigarettes per day (vs. $\leq 9$ ) were also associated with a statistically 


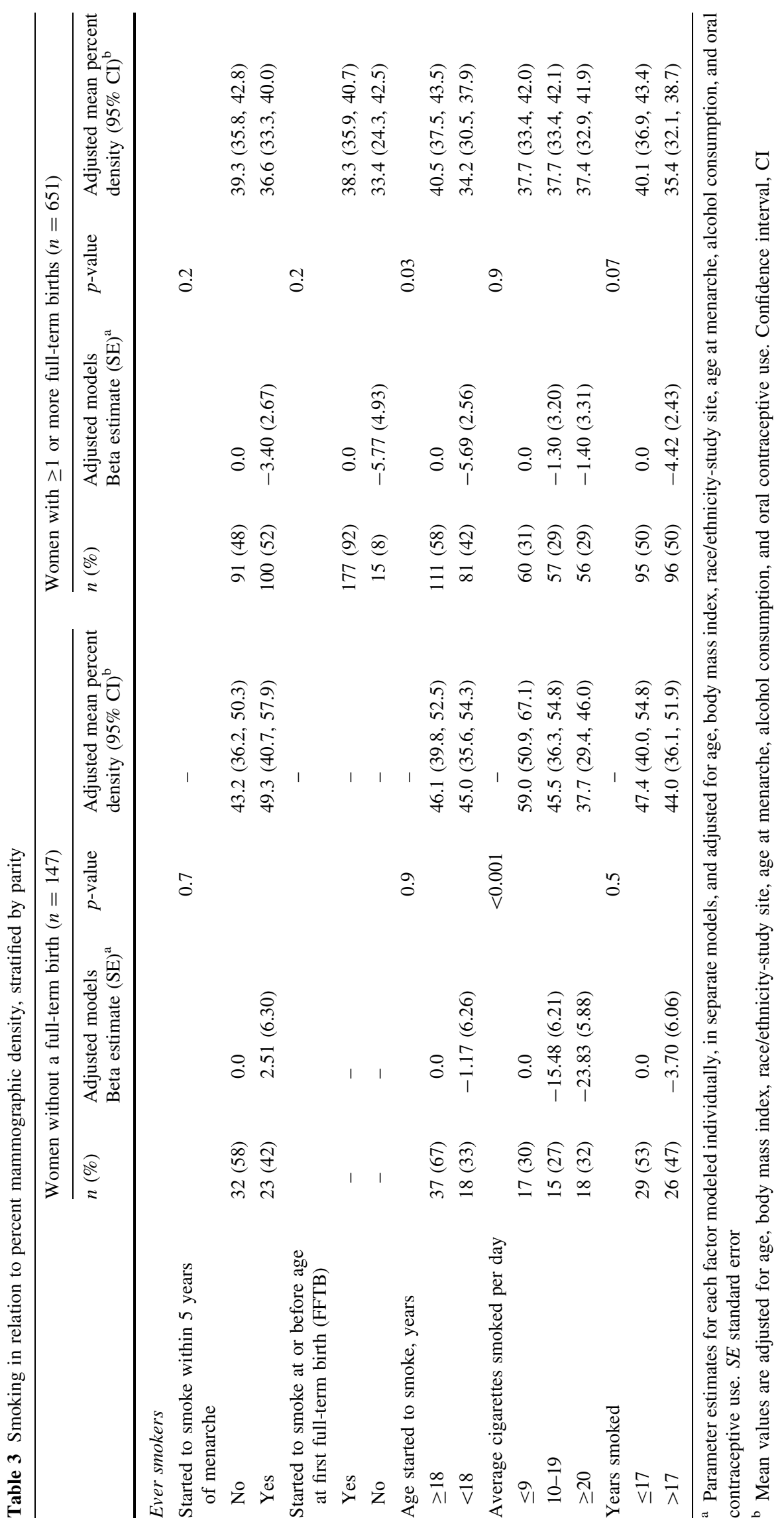


significant lower percent density among ever-active smokers. Starting to smoke during puberty or pre-partum, and duration of SHS exposure among never-active smokers were not positively associated with percent density in our data.

Our finding of an inverse association between currentactive smoking and percent mammographic density supports most [28-31] but not all [33] prior study results. The latter study finding may have been subject to measurement error [49] because smoking status was crudely defined as yes/no current smoker based on medical record data [33]. Our findings of inverse associations between mammographic density and earlier age at starting to smoke and for more cigarettes smoked per day, and no association with smoking duration were similar to findings from previously published results among pre- and postmenopausal women $[28,29]$.

We observed an interaction by parity for the association between smoking intensity and percent density, with a 23.8 percent lower density among nulliparous, ever-active smokers for 20 or more cigarettes per day (vs. $\leq 9$ ), and no association among parous, ever-active smokers. Breast tissue has a greater number of undifferentiated structures prior to a woman's first pregnancy [8] and is therefore more susceptible to the effects of tobacco during this period [50]. Our findings suggest that a long duration of exposure, at high smoking intensity, to undifferentiated breast tissue, is necessary to observe the strongest antiestrogenic effects of smoking on breast density among premenopausal women. These findings, however, should be interpreted cautiously because the association among nulliparous women was based on only 18 women.

Cigarette smoke may exert antiestrogenic effects by influencing estrogen metabolism. Cigarette smoke constituents, such as 3-methylcholanthrene and benzo(a)pyrene, are potent inducers of cytochrome p450 (CYP) 1A1 [5153], the primary enzyme responsible for 2-hydroxylation [54]. Estradiol 2-hydroxylation yields metabolites, such as [2-hydroxyestrone (2-OHE)], that have antiestrogenic properties [55]. Our group has previously reported a statistically significant trend $(p<0.0001)$ of increasing urinary 2-OHE level with increasing amount of smoking among pre- and early perimenopausal women in SWAN [56]. Although it remains a possibility that smoking reduces circulating estrogens by increasing excretion of estrogen metabolites, the effect of smoking is likely to be small.

The consideration of estrogen-alternative mechanisms that explain the inverse association between smoking and breast density is also relevant, given that the evidence for endogenous estrogen levels and mammographic density among premenopausal women is equivocal [57-59]. For example, an estrogen-alternative mechanism for smoking and density may involve the breast mitogen, insulin-like growth factor-1 (IGF-1). IGF-1 levels are positively associated with mammographic density [60], and lower levels have been reported among current smokers [61-63].

Although experimental data indicate that cigarette smoke suppresses adipogenesis [64], or the development of fat cells from pre-adipocytes, we observed that active smokers were more likely to have a BMI over $30 \mathrm{~kg} / \mathrm{m}^{2}$ compared to never-active smokers. We adjusted for BMI in our final models, because body size has a strong, inverse association with lower percent mammographic density [65]. However, there is still a small possibility that the observed inverse association between current smoking and mammographic density in our data was due in part to residual confounding by body size.

The strengths of our study included detailed active smoking information that provided the ability to examine multiple aspects of smoking exposure, and timing with menstrual and reproductive events. In addition, we collected SHS information based on exposure in the home, work, and other locations. A limitation, however, was that the SHS exposure data were ultimately based on self-report and only assessed at baseline and follow-up visit 03 . Although we used questions that have previously been validated with nicotine measures [40], and we estimated a relatively small change in SHS smoking status during follow-up in the cohort, we cannot exclude the possibility that our finding for no association with duration of SHS exposure was due, in part, to non-differential misclassification. Our study power to assess differences between current and former active smokers for smoking characteristics was limited due to our relatively small percentage (9\%) of current-active smokers. However, our findings for ever-active smokers were consistent with a previous study of similar study size, with $34 \%$ current smokers, for smoking characteristics among current smokers and percent density [28]. Although the multiethnic nature of our cohort improved the generalizability of our findings to the US population, our small numbers of African-Americans and Japanese, for example, may have limited our ability to fully adjust for confounding by race/ethnicity.

\section{Conclusions}

In our cohort of pre- and perimenopausal women, we observed statistically significant inverse associations with percent mammographic density for current-active smoking, starting to smoke before age 18 and smoking 20 or more cigarettes per day, and no association with duration of SHS exposure among never-active smokers. In addition, we observed a statistically significant interaction with parity where mammographic density was lower among nulliparous but not parous smokers. This observation, although 
supportive of an antiestrogenic effect of smoking on breast tissue, is counter to the known increased risk of breast cancer associated with smoking prior to FFTB. Thus, we conclude that the antiestrogenic but not the carcinogenic effects of smoking may be reflected by breast density.

Acknowledgments The Study of Women's Health Across the Nation (SWAN) has grant support from the National Institutes of Health (NIH), DHHS, through the National Institute on Aging (NIA), the National Institute of Nursing Research (NINR) and the NIH Office of Research on Women's Health (ORWH) (Grants NR004061; AG012505, AG012535, AG012531, AG012539, AG012546, AG012553, AG012554, AG012495). The content of this manuscript is solely the responsibility of the authors and does not necessarily represent the official views of the NIA, NINR, ORWH or the NIH. This ancillary study was supported by National Cancer Institute grant R01CA89552. Lesley Butler was supported by National Institute of Child Health and Human Development's Building Interdisciplinary Research Careers in Women's Health (BIRCWH) grant 5K12HD051958. Carolyn Crandall was supported by National Institutes of Health research grant 5K12AG01004 from the National Institute on Aging. Special thanks to The Whiteley Center at the University of Washington's Friday Harbor Laboratories, for providing a working environment conducive to completing this manuscript.

Clinical Centers University of Michigan, Ann Arbor-MaryFran Sowers, PI; Massachusetts General Hospital, Boston, MA-Robert Neer, PI 1994-1999; Joel Finkelstein, PI 1999- present; Rush University, Rush University Medical Center, Chicago, IL-Lynda Powell, PI 1994-2009; Howard Kravitz, PI 2009; University of California, Davis/Kaiser-Ellen Gold, PI; University of California, Los Angeles-Gail Greendale, PI; University of Medicine and Dentistry-New Jersey Medical School, Newark-Gerson Weiss, PI 1994-2004; Nanette Santoro, PI 2004 - present; and the University of Pittsburgh, Pittsburgh, PA-Karen Matthews, PI.

NIH Program Office National Institute on Aging, Bethesda, MD-Marcia Ory 1994-2001; Sherry Sherman 1994-present; National Institute of Nursing Research, Bethesda, MD-Program Officers.

Central Laboratory University of Michigan, Ann Arbor-Daniel McConnell (Central Ligand Assay Satellite Services).

Coordinating Center New England Research Institutes, Watertown, MA-Sonja McKinlay, PI 1995-2001; University of Pittsburgh, Pittsburgh, PA—Kim Sutton-Tyrrell, PI 2001—present.

\section{Steering Committee Chris Gallagher, Chair; Susan Johnson, Chair.}

We thank the study staff at each site and all the women who participated in SWAN.

Open Access This article is distributed under the terms of the Creative Commons Attribution Noncommercial License which permits any noncommercial use, distribution, and reproduction in any medium, provided the original author(s) and source are credited.

\section{References}

1. Hecht SS (2003) Tobacco carcinogens, their biomarkers and tobacco-induced cancer. Nat Rev 3(10):733-744
2. el-Bayoumy K (1992) Environmental carcinogens that may be involved in human breast cancer etiology. Chem Res Toxicol 5(5):585-590

3. Johnson KC (2005) Accumulating evidence on passive and active smoking and breast cancer risk. Int J Cancer 117(4):619-628

4. Terry PD, Rohan TE (2002) Cigarette smoking and the risk of breast cancer in women: a review of the literature. Cancer Epidemiol Biomarkers Prev 11(10 Pt 1):953-971

5. Morabia A (2002) Smoking (active and passive) and breast cancer: epidemiologic evidence up to June 2001. Environ Mol Mutagen 39(2-3):89-95

6. IARC Monographs on the evaluation of carcinogenic effects on humans (2004) Vol. 28: Tobacco smoke and involuntary smoking. IARC, Lyon, France

7. Phillips DH, Garte S (2008) Smoking and breast cancer: is there really a link? Cancer Epidemiol Biomarkers Prev 17(1):1-2

8. Russo J, Moral R, Balogh GA, Mailo D, Russo IH (2005) The protective role of pregnancy in breast cancer. Breast Cancer Res 7(3):131-142

9. Ha M, Mabuchi K, Sigurdson AJ et al (2007) Smoking cigarettes before first childbirth and risk of breast cancer. Am J Epidemiol 166(1):55-61

10. Gram IT, Braaten T, Terry PD et al (2005) Breast cancer risk among women who start smoking as teenagers. Cancer Epidemiol Biomarkers Prev 14(1):61-66

11. Reynolds P, Hurley S, Goldberg DE et al (2004) Active smoking, household passive smoking, and breast cancer: evidence from the California Teachers Study. J Natl Cancer Inst 96(1):29-37

12. Egan KM, Stampfer MJ, Hunter D et al (2002) Active and passive smoking in breast cancer: prospective results from the Nurses' Health Study. Epidemiology 13(2):138-145

13. Lash TL, Aschengrau A (1999) Active and passive cigarette smoking and the occurrence of breast cancer. Am J Epidemiol 149(1):5-12

14. Miller MD, Marty MA, Broadwin R et al (2007) The association between exposure to environmental tobacco smoke and breast cancer: a review by the California Environmental Protection Agency. Prev Med 44(2):93-106

15. Wells AJ (1998) Re: "Breast cancer, cigarette smoking, and passive smoking". Am J Epidemiol 147(10):991-992

16. Baron JA, La Vecchia C, Levi F (1990) The antiestrogenic effect of cigarette smoking in women. Am J Obstet Gynecol 162(2):502-514

17. Blake CA, Scaramuzzi RJ, Norman RL, Kanematsu S, Sawyer CH (1972) Nicotine delays the ovulatory surge of luteinizing hormone in the rat. Proc Soc Exp Biol Med 141(3):10141016

18. Blake CA, Scaramuzzi RJ, Norman RL, Kanematsu S, Sawyer CH (1972) Effect of nicotine on the proestrous ovulatory surge of LH in the rat. Endocrinology 91(5):1253-1258

19. Fuxe K, Andersson K, Eneroth P, Harfstrand A, Agnati LF (1989) Neuroendocrine actions of nicotine and of exposure to cigarette smoke: medical implications. Psychoneuroendocrinology 14(1-2):19-41

20. Khaw KT, Tazuke S, Barrett-Connor E (1988) Cigarette smoking and levels of adrenal androgens in postmenopausal women. N Engl J Med 318(26):1705-1709

21. Mlynarcikova A, Fickova M, Scsukova S (2005) Ovarian intrafollicular processes as a target for cigarette smoke components and selected environmental reproductive disruptors. Endocr Regul 39(1):21-32

22. Kaufman DW, Slone D, Rosenberg L, Miettinen OS, Shapiro S (1980) Cigarette smoking and age at natural menopause. Am J Public Health 70(4):420-422

23. Wong PK, Christie JJ, Wark JD (2007) The effects of smoking on bone health. Clin Sci (Lond) 113(5):233-241 
24. Westhoff C, Gentile G, Lee J, Zacur H, Helbig D (1996) Predictors of ovarian steroid secretion in reproductive-age women. Am J Epidemiol 144(4):381-388

25. Sterzik K, Strehler E, De Santo M et al (1996) Influence of smoking on fertility in women attending an in vitro fertilization program. Fertil Steril 65(4):810-814

26. MacMahon B, Trichopoulos D, Cole P, Brown J (1982) Cigarette smoking and urinary estrogens. N Engl J Med 307(17):10621065

27. Boyd NF, Lockwood GA, Byng JW, Tritchler DL, Yaffe MJ (1998) Mammographic densities and breast cancer risk. Cancer Epidemiol Biomarkers Prev 7(12):1133-1144

28. Bremnes Y, Ursin G, Bjurstam N, Gram IT (2007) Different measures of smoking exposure and mammographic density in postmenopausal Norwegian women: a cross-sectional study. Breast Cancer Res 9(5):R73

29. Vachon CM, Kuni CC, Anderson K, Anderson VE, Sellers TA (2000) Association of mammographically defined percent breast density with epidemiologic risk factors for breast cancer (United States). Cancer Causes Control 11(7):653-662

30. Jeffreys M, Warren R, Gunnell D, McCarron P, Smith GD (2004) Life course breast cancer risk factors and adult breast density (United Kingdom). Cancer Causes Control 15(9):947-955

31. Gapstur SM, Lopez P, Colangelo LA, Wolfman J, Van Horn L, Hendrick RE (2003) Associations of breast cancer risk factors with breast density in Hispanic women. Cancer Epidemiol Biomarkers Prev 12(10):1074-1080

32. Modugno F, Ngo DL, Allen GO et al (2006) Breast cancer risk factors and mammographic breast density in women over age 70 . Breast Cancer Res Treat 97(2):157-166

33. Roubidoux MA, Kaur JS, Griffith KA, Stillwater B, Novotny P, Sloan J (2003) Relationship of mammographic parenchymal patterns to breast cancer risk factors and smoking in Alaska Native women. Cancer Epidemiol Biomarkers Prev 12(10):10811086

34. Sowers MF, Crawford S, Sternfeld B (2000) SWAN: a multicenter, multi-ethnic, community-based cohort study of women and the menopausal transition. In: Lobo RA, Kelsey J, Marcus R et al (eds) Menopause: biology and pathobiology. Academic Press, New York, pp 175-188

35. Boyd N, Martin L, Stone J, Little L, Minkin S, Yaffe M (2002) A longitudinal study of the effects of menopause on mammographic features. Cancer Epidemiol Biomarkers Prev 11(10 Pt 1):10481053

36. Sowers MR, La Pietra MT (1995) Menopause: its epidemiology and potential association with chronic diseases. Epidemiol Rev 17(2):287-302

37. Dudley EC, Hopper JL, Taffe J, Guthrie JR, Burger HG, Dennerstein L (1998) Using longitudinal data to define the perimenopause by menstrual cycle characteristics. Climacteric 1(1): $18-25$

38. Brambilla DJ, McKinlay SM, Johannes CB (1994) Defining the perimenopause for application in epidemiologic investigations. Am J Epidemiol 140(12):1091-1095

39. Ferris BG (1978) Epidemiology standardization project (American Thoracic Society). Am Rev Respir Dis 118(6 Pt 2):1-120

40. Coghlin J, Hammond SK, Gann PH (1989) Development of epidemiologic tools for measuring environmental tobacco smoke exposure. Am J Epidemiol 130(4):696-704

41. Wellings SR, Wolfe JN (1978) Correlative studies of the histological and radiographic appearance of the breast parenchyma. Radiology 129(2):299-306

42. Haiman CA, Bernstein L, Berg D, Ingles SA, Salane M, Ursin G (2002) Genetic determinants of mammographic density. Breast Cancer Res 4(3):R5
43. Boyd NF, Martin LJ, Yaffe MJ, Minkin S (2006) Mammographic density: a hormonally responsive risk factor for breast cancer. J Br Menopause Soc 12(4):186-193

44. Byrne C, Schairer C, Wolfe J et al (1995) Mammographic features and breast cancer risk: effects with time, age, and menopause status. J Natl Cancer Inst 87(21):1622-1629

45. Greendale GA, Palla SL, Ursin G et al (2005) The association of endogenous sex steroids and sex steroid binding proteins with mammographic density: results from the postmenopausal estrogen/progestin interventions mammographic density study. Am J Epidemiol 162(9):826-834

46. Habel LA, Capra AM, Oestreicher N et al. (2007) Mammographic density in a multiethnic cohort. Menopause

47. Butler LM, Gold EB, Greendale GA et al. (2007) Menstrual and reproductive factors in relation to mammographic density: the Study of Women's Health Across the Nation (SWAN). Breast Cancer Res Treat

48. Butler LM, Gold EB, Greendale GA et al (2008) Menstrual and reproductive factors in relation to mammographic density: the Study of Women's Health Across the Nation (SWAN). Breast Cancer Res Treat 112(1):165-174

49. Mant J, Murphy M, Rose P, Vessey M (2000) The accuracy of general practitioner records of smoking and alcohol use: comparison with patient questionnaires. J Public Health Med 22(2):198-201

50. Russo J, Russo IH (2008) Breast development, hormones and cancer. Adv Exp Med Biol 630:52-56

51. Conney AH (1967) Pharmacological implications of microsomal enzyme induction. Pharmacol Rev 19(3):317-366

52. Whitlock JP Jr (1999) Induction of cytochrome P4501A1. Annu Rev Pharmacol Toxicol 39:103-125

53. Ma Q (2001) Induction of CYP1A1. The AhR/DRE paradigm: transcription, receptor regulation, and expanding biological roles. Curr Drug Metab 2(2):149-164

54. Tsuchiya Y, Nakajima M, Yokoi T (2005) Cytochrome P450mediated metabolism of estrogens and its regulation in human. Cancer Lett 227(2):115-124

55. Schneider J, Huh MM, Bradlow HL, Fishman J (1984) Antiestrogen action of 2-hydroxyestrone on MCF-7 human breast cancer cells. J Biol Chem 259(8):4840-4845

56. Sowers MR, Crawford S, McConnell DS et al (2006) Selected diet and lifestyle factors are associated with estrogen metabolites in a multiracial/ethnic population of women. J Nutr 136(6):1588-1595

57. Walker K, Fletcher O, Johnson N et al (2009) Premenopausal mammographic density in relation to cyclic variations in endogenous sex hormone levels, prolactin, and insulin-like growth factors. Cancer Res 69(16):6490-6499

58. Noh JJ, Maskarinec G, Pagano I, Cheung LW, Stanczyk FZ (2006) Mammographic densities and circulating hormones: a crosssectional study in premenopausal women. Breast 15(1):20-28

59. Boyd NF, Stone J, Martin LJ et al (2002) The association of breast mitogens with mammographic densities. $\mathrm{Br} \mathrm{J}$ Cancer 87(8):876-882

60. Martin LJ, Boyd NF (2008) Mammographic density. Potential mechanisms of breast cancer risk associated with mammographic density: hypotheses based on epidemiological evidence. Breast Cancer Res 10(1):201

61. dos Santos Silva I, Johnson N, De Stavola B et al (2006) The insulin-like growth factor system and mammographic features in premenopausal and postmenopausal women. Cancer Epidemiol Biomarkers Prev 15(3):449-455

62. Barnes BB, Chang-Claude J, Flesch-Janys D et al. (2009) Cancer risk factors associated with insulin-like growth factor (IGF)-I and IGF-binding protein-3 levels in healthy women: effect modification by menopausal status. Cancer Causes Control 
63. Helle SI, Ekse D, Holly JM, Lonning PE (2002) The IGF-system in healthy pre- and postmenopausal women: relations to demographic variables and sex-steroids. J Steroid Biochem Mol Biol 81(1):95-102

64. Shimada T, Hiramatsu N, Hayakawa K et al (2009) Dual suppression of adipogenesis by cigarette smoke through activation of the aryl hydrocarbon receptor and induction of endoplasmic reticulum stress. Am J Physiol Endocrinol Metab 296(4):E721E730

65. Boyd NF, Martin LJ, Sun L et al (2006) Body size, mammographic density, and breast cancer risk. Cancer Epidemiol Biomarkers Prev 15(11):2086-2092 